\title{
Surfaces
}

\section{GOING ELECTRONIC: THE BRYN MAWR CLASSICAL REVIEW}

\section{James J. O'Donnell}

Volume 4, 1994

SUR LA PUBLICATION ÉLECTRONIQUE

ON ELECTRONIC PUBLICATION

URI : https://id.erudit.org/iderudit/1064956ar

DOI : https://doi.org/10.7202/1064956ar

Aller au sommaire du numéro

Éditeur(s)

Les Presses de l’Université de Montréal

ISSN

1188-2492 (imprimé)

1200-5320 (numérique)

Découvrir la revue

Citer cet article

O'Donnell, J. J. (1994). GOING ELECTRONIC: THE BRYN MAWR CLASSICAL

REVIEW. Surfaces, 4. https://doi.org/10.7202/1064956ar
Résumé de l'article

Une discussion des transformations qu'entraîne la publication électronique illustrée par le cas particulier du récent passage au mode électronique de la Bryn Mawr Classical Review. d'utilisation que vous pouvez consulter en ligne. 
Going Electronic

GOING ELECTRONIC:

THE BRYN MAWR CLASSICAL REVIEW

James J. O'Donnell

ABSTRACT

A discussion of the shift that electronic publishing represents, with particular reference to the history of the Bryn Mawr Classical Review and the effect of its shift to electronic publication.

\section{RÉSUMÉ}

Une discussion des transformations qu'entraîne la publication électronique illustrée par le cas particulier du récent passage au mode électronique de la Bryn Mawr Classical Review.

We live in an age of media transition not unlike that which ushered in the print culture so familiar to us all. It is instructive to compare the objections raised in those days to print with those raised now to electronic media: the resemblances are eery. Just last week, I had a Marxist literary scholar saying to me words that quite unconsciously and quite faithfully echoed the lament of a 15th century Benedictine abbot for the threatened decay of the medieval scriptorium. For the objections raised in both ages speak not so much to real drawbacks in the new medium as to the threat they pose to the 
existing social order. All my work in electronic scholarly communication has been dedicated to finding ways to adapt the new media and the old scholarly institutions to each other, in the hope that what survives will preserve what is valuable of the old and at the same time find new vitality for the life of the mind in the exploitation of the possibilities of information technology. It is in this spirit that I present the following reflection on my experiences as editor of the Bryn Mawr Classical Review.

BMCR was conceived in the summer of 1990 as a paper periodical publishing timely book reviews in Greek and Latin classics (more or less excluding archaeology), somewhat on the model of Religious Studies Review. Very short reviews were envisioned. The first issue appeared in November 1990. Since that date, 20 issues of the paper journal have appeared, comprising approximately 425 book reviews and a small number (less than 50 perhaps in all) of informal essays, replies by aggrieved authors, conference reports, and other more or less ephemeral material of interest to our readers. The reviews are substantial, often essay-length. Average length is perhaps $1500-2000$ words.

For the first year, free subscriptions were given to every classics department in North America known to us; paper subscriptions then began at a rate of $\$ 10$ per year and is now $\$ 15$ a year. Though conceived as a paper journal, from the first issue we have also distributed all of BMCR by e-mail over the internet. Everything that appears in print goes out by e-mail, and there are usually some additional items as well (not usually reviews, but ephemera). In the beginning, huge files duplicating the contents of a paper issue were shipped, but this was found undesirable for several reasons, so since early 1991, e-BMCR has been shipped one review at a time. Subscriptions are managed by a listserv program at Bryn Mawr's computer center. "Back issues" were for the first two years handled by individual requests to the eeditor, a trifling concern at the outset but increasingly wearying as time went on. Since 1993, back issues have been made available on-line through the facilities of the e-text center at the University of Virginia's Alderman Library and can be gotten at through ftp (file transfer protocol) or gopher (with WAIS-indexing to facilitate on-line searching for keywords).

E-subscriptions had reached 680 by summer 1993. At that time, we announced the establishment of Bryn Mawr Medieval Review, a clone dedicated to coverage of medieval studies; but BMMR produces only eversions and there are no plans for paper production. In addition, a notional third entity was created, "Bryn Mawr Reviews" (BMR) for those esubscribers who wanted to subscribe to both BMCR and BMMR without overlap. (Some reviews are sent to both lists, depending on content of the books in question: e.g., Epicureanism Ancient and Medieval would go to both. We also envision the possibility of other specialties joining the family, perhaps first archaeology with a BMAR, and BMR would remain the umbrella for those readers who wanted everything we produced.) At that 
point the subscription numbers for BMCR dropped slightly to about 630, but have since come back up, while BMR immediately acquired about 250 subscribers (some from BMCR) and BMMR alone another 250. As of October 10, 1993, the exact numbers are:

BMCR: 663

BMMR: 280

BMR: 277

Total: 1220

Beyond "subscribers" there is also an unknown number of readers approaching the files through gopher, etc. The University of Virginia Library tells us that we are regularly either the most or the second most frequently accessed electronic resource on their server, for example. In other ways the library community has helped shape our place as an "electronic journal". The ARL-published Directory of Electronic Journals, Newsletters, and Academic Discussion Lists has done much to build awareness of the format and thus in a real way to create a community of people who produce, manage, and consume such forms of scholarly discourse; other ARL activities, espeially those of the Office of Scientific and Academic Publishing (e.g., their e-publishing symposium meetings in D.C.) have been at the national center of community-building and consciousness-raising. Beside that, we have an ISSN for each of our three e-manifestations as well as for pBMCR, there are MARC-format catalogue records that give us visibility in the world of library catalogues, and numerous libraries have mechanisms in place to subscribe to us and redistribute our product to their readers. We started with a naive idea that we knew what our target audience was and how to reach it, but have become convinced that though you write for a target audience, a much larger and diverse group of readers will, given half a chance, find you and read you with interest.

Three editors and a managing editor for BMMR share the main workload for the journals: it must be emphasized that our time is not "free" (it is paid for by our institutions), but of course it is allocated to this activity at no cost to the journals themselves.

BMCR and BMMR have separate editorial advisory boards, each comprising about a dozen scholars of standing known to us personally. They commit to 
writing reviews themselves and to helping us find good reviewers. They also help as needed in evaluating reviews submitted and in discussing issues that arise when reviews are controversial. (On one occasion, for example, we deputized a scholar of high integrity to look at a book, the book's review, the author's comments on the review, and the reviewer's comments on the author's comments -- all to help us judge the merits of the case and to decide how to treat that reviewer's work in the future.)

Finally, our authors. In regularizing the paperwork surrounding our management of copyright assignments, we had the pleasant experience a few months ago of discovering that at the point when we had about 370 reviews published, those reviews had been written by no fewer than 130 different people, a much larger community already than we thought we had formed. Further, and most interesting, the community of readers and writers is gradually interpenetrating. We now distribute a monthly electronic file of "Books Received" with titles not yet assigned for review starred, asking readers to volunteer. Literally within minutes of shipping that file, requests come flying in from all over the world, and we have gotten some excellent new reviews and reviewers that way.

Total dollar costs of production are trivial, especially if the paper version is left aside. There are some funds available to the journals from an earlier desktop publishing enterprise at Bryn Mawr, and that pays a less-than-halftime student employee to do some keyboarding and other chores. The most substantial "economic" input into the system is the time and effort of the review authors (small amounts of time by a large number of people) and the editors (quite large amounts of time by a small number of people). This time and effort is paid for by the institutions that employ us and leave it to our discretion how to spend a substantial part of our time. It is our observation that there is a large reservoir of such time and talent underutilized in most academic institutions and that a structure of incentives that more effectively encouraged socially useful expenditure of time could be very helpful in more efficiently using resources already deployed.

\section{Prospects:}

As just noted, the enterprise is markedly dependent on the time and talent of the named individuals, who have that time to spend because of the willingness of their academic institu tions to leave it to their discretion how to spend their non-teaching professional energies. Nothing in the structure of the enterprise guarantees its perpetuation past the point at which these individuals are involved; experience with other electronic network collaborations is inconclusive on the point whether suitable replacement talent could be found. That would depend, inter alia $a_{\llcorner}$on the date at which 
the search needed to be made: as more and more academics come on line, the talent pool increases. (N.B.: there is an implicit assumption in such calculations that an entity such as BMCR has a presumptive right to continue to exist indefinitely. The long runs of old journals on our library shelves encourage us to imagine this form of eternal life. Would it be an advantage of e-publishing if such perpetuity were not the rule?)

We are discussing the preparation and distribution of an electronic hard copy, so to speak, comprising the archive of the first five years, presumably in CD-ROM form. We would expect "publication" and distribution of such an artifact through a traditional print publisher beginning to experiment with alternate forms.

The single greatest difficulty in electronic distribution is the handling of illustrative material and, most of all, Greek language text. There is no satisfactory way to distribute such material widely to our target audience at the present time, though this is as much a factor of the limited technical capacity of that specific audience as it is a technical difficulty per se. If we could define what equipment all our readers would have, then we could distribute a higher-quality electronic product with no difficulty.

\section{Most Important Lesson:}

One of us learned this lesson only because he was speaking to a room full of librarians and heard the words coming out of his own mouth. The success of BMCR has been rooted in the fact that it started with a good, but very oldfashioned, editorial judgment: that there was a place for this particular vision of a periodical, and that we had the resources to put it together. We did not begin as an experiment or a demonstration; we didn't think it would be nice to have an e-journal, and so try to whomp one together. We knew that book reviews came out too slowly and through too few channels in our field, and we knew that we had a network of friends and colleagues (an important nucleus was built up through our earlier desktop publishing experience with Bryn Mawr Commentaries) who would respond and write for us. Thus our success depends on our being a good product that meets a felt need. The electronic component has made it easier to do this in a hundred ways and to reach a wider audience more economically, and it promises to be an exciting way forward for the future, but we're not just doing this to show off a technology: we're doing this because people still read books and want to see them discussed in a timely and interesting way. 
No person is an island. In the world of print technology, it is easy to settle into a niche, compare oneself with others in the same niche, and contribute blindly to a system you never think about. When you move into a new environment, what suddenly becomes clear is that scholarly publishing is already a community of authors, editors, publishers, distributors, librarians, and readers. Given that scholarly publishing is by and large not a commercial enterprise but a partially or wholly subsidized one, no simple laissez-faire free market can be relied on to create a new community in an electronic environment. Cooperation, consultation, and attention to community-building are necessary elements. At the moment, librarians are doing more of that than anyone else, with university press publishers perhaps beginning to catch on a bit, and academics generally as both authors and users lagging far behind, and lagging still further behind them, deans, provosts, and academic administration generally. The most interesting large issues challenge us to think about what kind of system might emerge and how we can make that system as responsive as possible to the various needs of the existing constituencies.

\section{What now?}

The print version of BMCR is readily recognizable as a "book review journal", a phenomenon well-established in the world of print. The electronic version naturally resembles that, but the shift from one medium to another also brings important changes. Three points seem to us important.

i) BMCR belongs to that category of networked electronic publication that arises from the voluntary efforts of contributors, themselves mainly subsidized in their activity by their academic positions. The largest single capital resource we have is the sweat equity of ourselves and our nearly two hundred (so far) contributors. We believe that this quality of BMCR places us in an important and innovative niche in scholarly publishing. Our journal adds value to the scholarly publishing system at the addition of trivial net dollar costs. In fact, what we do is help the system get more value for the dollars already invested in salaries, libraries, etc. We have been able to offer a new outlet for scholarly discourse without further burdening the acquisitions budgets of libraries or threatening a traditional publisher with a deficit. This cannot be the only form of electronic scholarly publishing that develops, but we think that it is important to encourage this form of publication because of the relief it offers to the economic crisis of scholarly publishing outlined in the Mellon report of 1992. 
ii) BMCR further has a very different effect in e-form from that of traditional print journals. It stimulates dialogue in many ways: in encouraging multiple reviews of the same book, in actively soliciting responses to reviews from authors and other interested parties, in publishing columns of current news and opinion about the state of the classical profession, and in relaying important news in a timely way. We are creating a community of interest and discourse among classicists that has never existed before. (Just this month, we distributed a document announcing a continuing national colloquium on graduate education in classics that began with an informal meeting at Penn in November: we had dozens of e-mail replies and a full house at a meeting of interested parties at the APA convention this week in Washington, and will continue discussion by listserv and by periodic notices to BMCR subscribers.)

iii) The model is replicable. Our sibling BMMR already has begun to create the same kind of community among medievalists, and we have continuing discussions, none yet reaching maturity, with specialists in archaeology, Renaissance studies, and Romantic studies, about creating further sister publications under the Bryn Mawr Reviews (BMR) rubric. We are actively seeking such collaborators and believe that a family of such journals, overlapping in many fruitful ways (many reviews are now shipped both to BMCR and BMMR readers), can help create a wider community of interest among scholars in the humanities here and abroad. (Our subscribers today reach from the antipodes to South Africa to Poland and Scandinavia.)

We intend to go on as we have, providing the best quality service to the widest possible audience. We will actively pursue upgrading the visual quality of our product, and in particular seek to add reliable transmission of Greek-alphabet text, but we will not abandon the vt100 all-ASCII client base precipitously. We think therefore in the next year we will be offering something like a high-quality WWW approach, while still distributing material by listserv the old-fashioned way. We think that subscriptions are a good way of reaching an audience repeatedly, and listserv remains a functional tool for doing that.

\section{James J. O'Donnell \\ Professor of Classical Studies \\ Coordinator, Center for Computer Analysis of Texts}

University of Pennsylvania, Philadelphia

Internet: jod@ccat.sas.upenn.edu

Surface Page d'Accueil/Home Page 